\title{
Seepage Behavior of an Inclined Wall Earth Dam under Fluctuating Drought and Flood Conditions
}

\author{
Wei Ye, ${ }^{1}$ Fuheng Ma $\mathbb{D},{ }^{1,2}$ Jiang $\mathrm{Hu}\left(\mathbb{D},{ }^{1}\right.$ and Ziyang $\mathrm{Li}\left(\mathbb{D}{ }^{1}\right.$ \\ ${ }^{1}$ Nanjing Hydraulic Research Institute, Nanjing 210029, China \\ ${ }^{2}$ State Key Laboratory of Hydrology-Water Resources and Hydraulic Engineering, Nanjing 210029, China \\ Correspondence should be addressed to Jiang Hu; huj@nhri.cn
}

Received 8 January 2018; Revised 16 April 2018; Accepted 30 April 2018; Published 9 July 2018

Academic Editor: Kuo-Hsin Yang

Copyright (C) 2018 Wei Ye et al. This is an open access article distributed under the Creative Commons Attribution License, which permits unrestricted use, distribution, and reproduction in any medium, provided the original work is properly cited.

\begin{abstract}
Most dam seepage safety analyses evaluate a stable seepage field, infiltration line, and seepage flow. However, under fluctuating drought-flood conditions, the soil surface becomes cracked, making it too complicated to conduct a routine seepage analysis. In this paper, the seepage characteristics of an inclined wall dam under fluctuating drought-flood conditions were studied using a large-scale physical model. The results show that after drought, the permeability coefficient of clay with low crack development was smaller than that of the saturated permeability, but for cracked areas, with high permeability, permeability coefficients were much larger than those of the saturated permeability. As the water level rose, cracks could heal themselves, but this healing was superficial, and the soil could no longer return to its predrought state. After crack healing, the integrity of the dam slope was much less than its original state. In addition, the formation of cracks increased the porosity of the soil and changed the soil permeability, which permanently weakened the antiseepage performance of the clay soil. This study evaluated the seepage flow behavior of an inclined wall dam under fluctuating drought-flood conditions, and results can be used to monitor and protect the weak parts of seepage dams in practical engineering projects.
\end{abstract}

\section{Introduction}

Influenced by global climate change, the frequency of extreme events like droughts and floods is increasing $[1,2]$, and the cycle is getting shorter and shorter $[3,4]$. These extreme events bring great challenges for water conservancy facilities, especially for earth dams. By analyzing climate status charts and comparing the highest and the lowest dam failure rates in Shanxi and Hunan Province, China, respectively, it was found that a large amount of precipitation after a long dry period will increase the risk of reservoir failure accidents [5,6]. Therefore, a study on the effects of fluctuating drought-flood conditions on the safety of dams is crucial.

In general, extreme events can be divided into two processes. The first is drought, and the second is heavy rainfall, causing flooding. Different processes have different influences on an earth dam, but the main effect of the whole sequence is the seepage problem, which is a very important factor leading to dam failure [7]. When suffering drought, the water level drops, and the reservoir is exhausted. Then, the low water level and drying of the reservoir cause cracks in the clay of the inclined wall and horizontal blanket structures. Development of cracks damages the continuity and integrity of the impermeable structures and weakens its antiseepage performance. So, a seepage analysis with the presence of cracks is of widespread concern.

For several decades, researchers have studied seepage through cracks and made fruitful advances. The occurrence of cracks changes the boundary conditions of the soil, thus affecting the infiltration of water flow. Based on this, seepage of water in cracked soil can be divided into two types: (a) vertical infiltration through the soil surface and (b) transverse seepage through cracks [8]. Moreover, the appearance of a crack breaks the integrity of the soil, so a discrete crack model was established based on the concept of discrete cracks to carry out seepage calculations [9]. This model elaborates the basic principle of two-phase seepage flow, and a finite element format of the model was established based on the Galerkin weighted residual method. When water flows into 


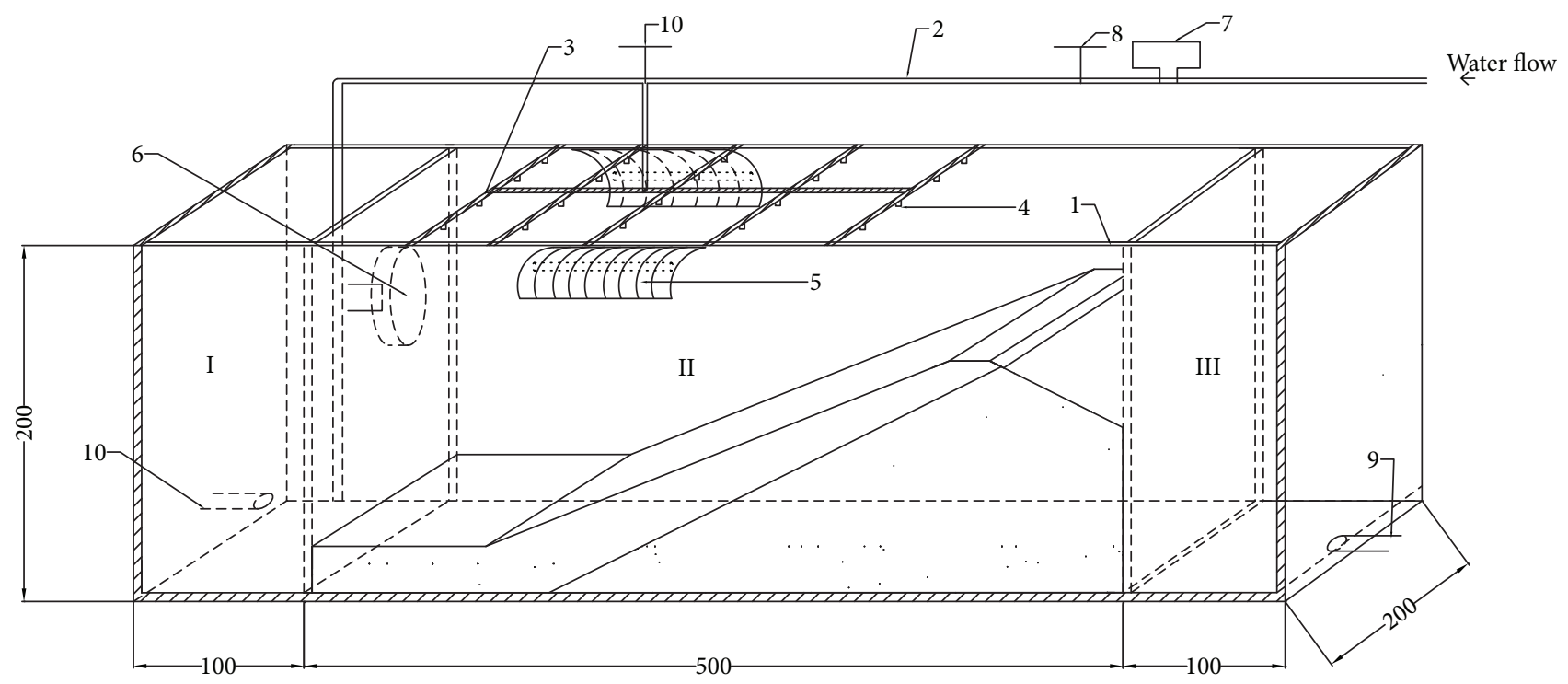

Figure 1: Model system (unit: $\mathrm{cm}$ ). 1: tempered glass cover, 2: water pipe, 3: rain line, 4: atomization nozzle, 5: long arc xenon lamp, 6: fan, 7: booster lamp, 8: flow meter, 9: drain hole, and 10: rainfall/impound valve.

a crack, the infiltration capacity in the cracks is controlled by several factors. To describe this phenomenon, the concept of critical rate of water-level rise was put forward by model tests, which illustrated that when the rate of water-level rise is faster than the critical value, fissure water flow rate increases, and the relationship between the water flow and the water level is not positive [10]. For different forms of cracks, to find out what factors affect infiltration, and considering the impact of crack parameters on water flow, a single crack test model was conducted using test equipment designed by Fan [11]. By changing the depth of the crack and the height of the water level, the relationships among infiltration volume, crack height, permeability coefficient, and crack depth were obtained. Water infiltration changes the moisture content of cracked soil, and this change determines the development of cracks, which influences seepage behavior. This is an interactive process [12]. Therefore, to accurately reflect the influence of crack position and size on seepage flow, Liu [13] calculated the permeability pressure and infiltration line and leakage of an inclined wall, from the perspective of a single crack, taking crack location and crack width as parameters. Using the method of superposition, he obtained the pressure distribution and seepage flow of multiple different positions and widths. Additionally, to investigate the influence of crack depth on the hydrodynamic characteristics of soil under flood conditions, Khandelwal et al. [14] proposed a two-dimensional numerical model to analyze the change in seepage for random crack depths. However, moisture contents increased linearly with depth and then sharply decreased at what was interpreted to be the bottom of the crack, and longitudinal tension cracks at or near the crest of a slope or earth embankment did not appear to relate to the development of a Rankine failure state in the underlying soil [15]. When they develop past a certain degree, cracks in a clay blanket can damage its impermeable barrier. The penetrating cracks may lead to an increase of seepage pressure and leakage, causing the hazard of seepage failure. Therefore, the formation of cracks changes the method of water infiltration, and the crack morphology affects the method of water infiltration. Combined with a continuous change in external water level, seepage analysis of cracked soil becomes very complex.

Current research on seepage in cracked soil mainly has focused on crack development, calculations of crack seepage, and the effect of crack parameters on seepage flow [16-19], and the occurrence of heavy rainfall immediately after a drought and comparisons of seepage flow during different periods under these conditions have rarely been considered. Therefore, taking an inclined wall dam as an example, this study simulated fluctuating drought-flood conditions and evaluated the seepage behavior of the impermeable structure.

\section{Materials and Methods}

2.1. Testing System. The test compartment, as shown in Figure 1, was divided into two systems to simulate the fluctuating drought-flood conditions: the drying system, which consists of a long arc xenon lamp and fan to simulate drought, and the rainfall system, which contains a booster pump, flow meter, and rainfall pipeline to simulate heavy rainfall. The test compartment has external dimensions of $700 \mathrm{~cm} \times 200 \mathrm{~cm} \times 200 \mathrm{~cm}$ (length $\times$ width $\times$ height), divided into three sections. Section I is $100 \mathrm{~cm}$ in length, and it can accommodate direct water injection when the water level is required to rise rapidly. Section II is $500 \mathrm{~cm}$ in length, where instruments are installed and the model operates. Section III is $100 \mathrm{~cm}$ in length, and it is used to discharge the water infiltrated from upstream to downstream. The outer walls of the test compartment are made of tempered glass to facilitate the observation of internal model filling and to control the water level. To avoid the direct erosion of soil by rainwater, atomization nozzles were adopted. Instruments 
used in the test included osmometers, soil pressure gauges, and matric suction sensors. Parameters of each instrument are shown in Table 1.

\subsection{Testing Model}

2.2.1. Similarity of the Model. The production of this test model is based on the first, second, and third similarity theorems in geometry. Model parameters that needed to be considered include density $\rho$, cohesion $c$, internal friction angle $\phi$, permeability coefficient $k$, dimension $L$, side pressure $p$, and time $t$. After calculation, the similarity ratios of $\phi, c$, and $\rho$ are 1 , which are in line with those in the practical engineering site at Zhaopingtai Reservoir in He'nan Province, China. The similarity ratio of $t$ and $k$ was $\sqrt{n}$. To satisfy the geometric similarity, the size of the model was reduced by 1:28 during the design phase. The clay soil used in the test was selected from the actual project site, and therefore the density of the soil samples was consistent with the site to ensure that the model had the same degree of compaction as the original soil. The water level in the test corresponds to the measured water level in the actual reservoir, at a ratio of $1: 28$. Additionally, sensors were installed as far as possible from the boundary so that the measurement results would be less affected by the boundary.

2.2.2. Model Production. The soil samples used in the test were excavated from the upstream dam slope of Zhaopingtai Reservoir in He'nan Province, China, and they mainly consisted of clay (23\%) and silt (46.8\%), with some sand (18.5\%) and gravel (11.7\%). The particle size distribution of soil is shown in Table 2 and Figure 2. The liquid limit and plasticity index of the soil were $30.8 \%$ and $17.1 \%$, respectively, and the optimum moisture content and the maximum dry density were $19.2 \%$ and $1.4 \mathrm{~g} / \mathrm{cm}^{3}$, respectively. The nonuniform coefficient was 17.5 (bigger than 5), and the curvature coefficient was 0.914 (close to 1), indicating that the soil body was easily compacted. The basic parameters of the soil are presented in Table 3.

The whole model was $165 \mathrm{~cm}$ in height, and the clay blanket was $40 \mathrm{~cm}$ thick and $110 \mathrm{~cm}$ long. Upstream and downstream slope gradients of the inclined wall were $1: 2.5$ and $1: 2$, respectively (Figure 3 ). The dam model was constructed by layers. To control the height of each layer, the elevation was marked on the outside wall of the tempered glass for reference. After the completion of the sand filling at the back end of the model, considering the difference in permeability coefficients between sand and clay, a mixed transition layer, about $10 \mathrm{~cm}$ thick, was added over the fine sand soil. After that, the clay blanket was added to the transitional material, and the slope gradient of the upstream side was $1: 2.5$. However, because of the layered filling, it was difficult to control the slope of each layer, so after the whole construction was completed, slope shaping was carried out. Due to concern that burial of instruments would affect the quality of filling, the installation of instruments was carried out after the model filling was completed. All sensors embedded in the clay blanket and sand soil were at the same height,
TABLE 1: Test instrument parameters.

\begin{tabular}{lccc}
\hline Sensor & Type & Range $(\mathrm{kPa})$ & Precision \\
\hline Osmometer & BWMK-0.015 & $0 \sim 40$ & $\pm 0.05 \% \mathrm{~F} \cdot \mathrm{S}$ \\
Earth pressure gauge & BW-0.2 & $0 \sim 600$ & $\pm 0.05 \% \mathrm{~F} \cdot \mathrm{S}$ \\
Matric suction sensor & FTC-100 & $1 \sim 1500$ & $\pm 5 \% \mathrm{~F} \cdot \mathrm{S}$ \\
\hline
\end{tabular}

located $10 \mathrm{~cm}$ up from the bottom of the model. Osmometers were buried downstream of the matric suction sensors, as shown in Figures 4 and 5 (S: osmometer, Z: matric suction sensor, and T: soil pressure gauge). All instruments were connected to an automatic data acquisition system.

\section{Results and Discussion}

The test was carried out in three steps. The first was to impound water to form a stable seepage field in the dam body. The second was to simulate drought conditions to promote the development of cracks in the soil, and the third step was to simulate rainfall to create fluctuating drought-flood conditions. When the first step was finished, the test was suspended due to the Chinese traditional Spring Festival holiday and all instruments were powered off. The length of the holiday was 13 days (from January 23, 2017, to February 4, 2017). The other two processes were conducted after the holidays.

3.1. Impoundment Period. In the impoundment period, the water level in the upper reach was $1.2 \mathrm{~m}$ (Figure 6). Changes of pore water pressure, soil pressure, and matric suction in the dam are shown in Figure 7.

The impoundment process started with the water injection in section $I$, and then the water level rose to the same height as the front end of the clay blanket, so the pore water pressure at the front of the blanket changed first and then increased at a fast rate. Then, 6 hours later, except for the front of the clay blanket and middle of the inclined wall, pore water pressure at all parts changed simultaneously. This is mainly because the water level in the upper reach had already submerged the clay blanket 6 hours earlier, so some water was infiltrating into the blanket and the bottom of the inclined wall but was not yet penetrating the impermeable body into the sand layer. At this time, the water level had not reached the middle of the inclined wall, but the water had begun to penetrate the impermeable body to the sand layer. Subsequently, the water level remained unchanged for about 12 hours and then increased again, and values of pore water pressure remained steady for a while, after which they underwent a sharp increase. In this process, the water level rose to the design value of $1.2 \mathrm{~m}$, so in addition to the middle of the inclined wall, pore water pressure at all parts showed a dramatic upward trend and water seeped from the downstream end of the dam. Because of the high potential, no matter the change rate or amplitude, the pore water pressure in the middle of the inclined wall was smaller than that in other parts. The last stage of the test lasted for 50 hours, and then water in section I was drained, causing the water 


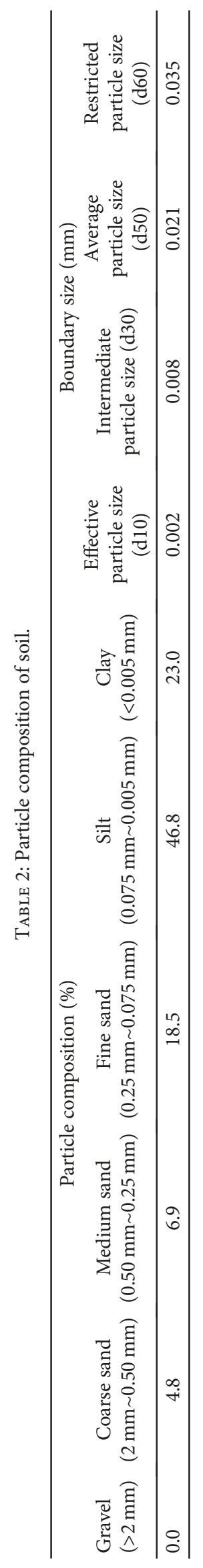




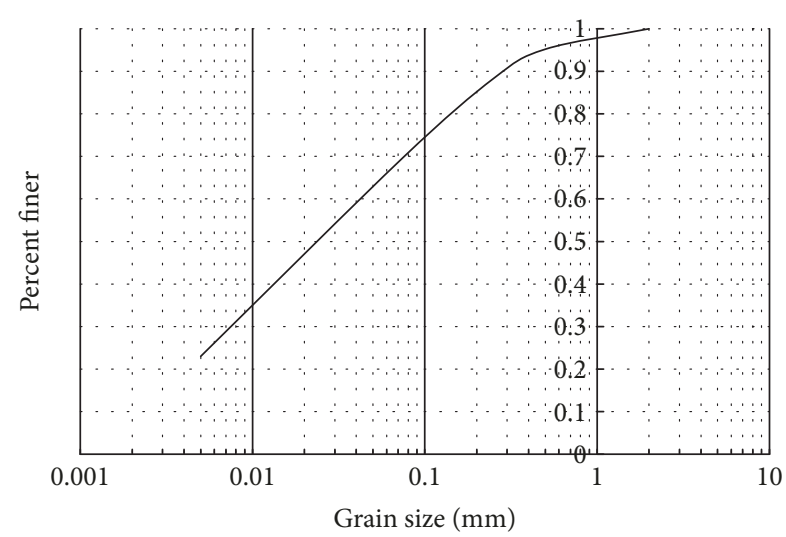

Figure 2: Particle size distribution.

TABle 3: Physical properties of the soil.

\begin{tabular}{lccc}
\hline $\begin{array}{l}\text { Moisture content } \\
w(\%)\end{array}$ & $\begin{array}{c}\text { Wet density } \\
\rho\left(\mathrm{g} / \mathrm{cm}^{3}\right)\end{array}$ & $\begin{array}{c}\text { Dry density } \\
\rho_{\mathrm{d}}\left(\mathrm{g} / \mathrm{cm}^{3}\right)\end{array}$ & $\begin{array}{c}\text { Saturation } \\
\text { permeability } \\
\text { coefficient } k(\mathrm{~cm} / \mathrm{s})\end{array}$ \\
\hline 18.1 & 1.65 & 1.40 & $1.69 \times 10^{-6}$ \\
\hline
\end{tabular}

level to drop rapidly, which resulted in a drop in pore water pressure.

For soil pressure, because the water content of the soil in upper part of the inclined wall did not change significantly after the impoundment, the soil weight did not change much as well, and the value of soil pressure basically remained steady. After the impoundment, due to the saturation and settling of sand in the lower layer, the clay layer was loosened and some settlement joints were formed in the middle of the dam. The widest settlement joint was located near the middle of the dam slope, from slightly above to slightly below the midpoint, and there were some transverse cracks near the vertical distribution of the main settlement joint. Formation of settlement joints resulted in large changes in soil pressure in the middle part of the inclined wall. As time went on, stress between the upper and lower parts of the settlement joints got smaller and smaller, and the pressure value in the middle decreased. Unlike the middle and upper parts, because of the increase in water content adding to the soil weight, the soil pressure at the lower part of the inclined wall increased. Thereafter, water in the dam body flowed out through the sand, and the weight of soil decreased, leading to the drop of soil pressure.

In many previous studies, it was mentioned that the matric suction in soil was affected by factors such as moisture content, confining pressure, and temperature. In this test, it took much time to make the dam model, so the moisture content of all parts could not be guaranteed the same. Affected by the filling quality and instrument embedment, the porosity was not uniform throughout the model. Also, the confining pressure at different locations was also slightly different. All of these factors have resulted in differences in initial matric suction across the dam model. Besides, the range of the FTC-100 sensor for measuring matric suction was 1 to $1500 \mathrm{kPa}$. The maximum difference of initial matric suction (except the crest) was about $20 \mathrm{kPa}$, which accounted for about $1.3 \%$ of the measuring range, while the sensor measurement accuracy was $\pm 5 \%$. Therefore, the difference of initial suction could be considered acceptable. In order to measure the matric suction more accurately, it was necessary to ensure a certain thickness of soil around the sensor. However, the thickness of the soil at the crest was thin, and the size of the sensor was relatively big (the thickness of the crest was $10 \mathrm{~cm}$, and the diameter of the instrument probe was about $6 \mathrm{~cm}$ ). Therefore, the measured data was uncertain at the crest. In this period, the initial impoundment process increased the moisture content of the soil and caused a decrease in matric suction everywhere. Specifically, for the clay blanket, affected by the front water level in the upper reach, the variation in matric suction was not very large, with an amplitude of around $10 \mathrm{kPa}$. For the inclined wall, the moisture content of the clay soil increased as the water level rose, and the amplitude of matric suction was around $20-30 \mathrm{kPa}$. Finally, for the dam crest, it could be found from the measurement results that the initial matric suction at the crest differed greatly from other parts, so that the matric suction at the crest could not be compared with the rest at other parts directly. In the process of testing, the researchers had to step on the soil mass to carry out related work at the top of the dam, which caused a decrease in the volume of soil, and as a result, the water content at the dam crest was relatively large and the suction became small.

3.2. Drought Period. The drought process and crack development are shown in Figure 8, and the results during this period are shown in Figure 9.

In the drought period, pore water pressure was roughly 0 , except at the front of the clay blanket and in the sand layer. Due to the limitation of the drain equipment, the water could not be completely drained out of sections I and III, and vaporized water liquefied on the insulating film and then fell back into sections I and III, so some water remained in those sections, although the water level was very low. Additionally, according to the osmometer data, the water stayed in a stable state, while in the dry soil, due to the limited precision of the instrument, measurements showed microfluctuations.

Compared with the soil pressure in the impoundment period, the soil pressure in the middle of the inclined wall changed from 0 to $5 \mathrm{kPa}$ after the saturation settling, and the measurements in the other parts basically maintained a stable state. As the test went on, soil pressure decreased, which resulted from the evaporation of water. After 4 days, the water content of the dam slope was measured, and this operation required test personnel to walk on the dam body, leading to a fluctuation in the soil pressure.

After the instruments were powered on in this period, a large change in the matric suction at the dam crest was found, confirming the uncertainty of the data measurement at the crest mentioned in Section 3.1. At the beginning of the drought, the suction value at the crest was close to that at other parts, but it was unreliable. The suction at the dam crest was only suitable for the observation of changes in the same process and could not be used to compare with each other across multiple periods. During this period, because water 


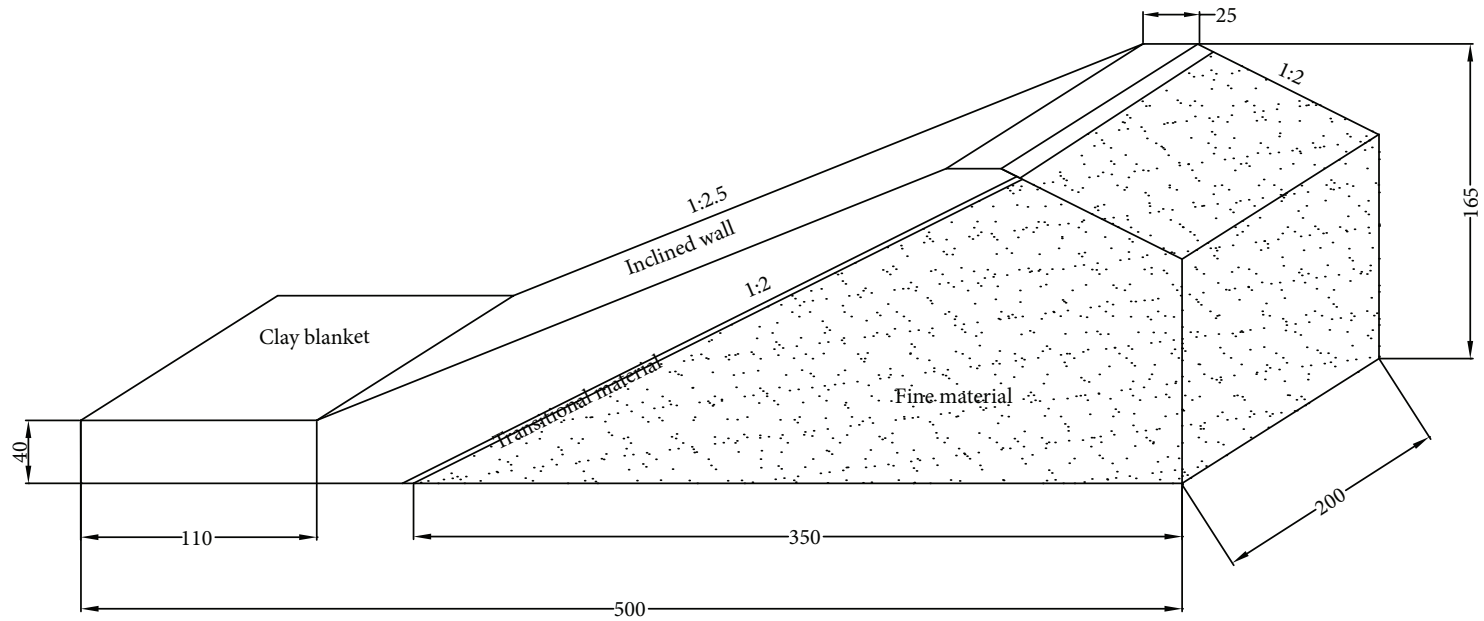

FIgURe 3: Test model (unit: $\mathrm{cm}$ ).

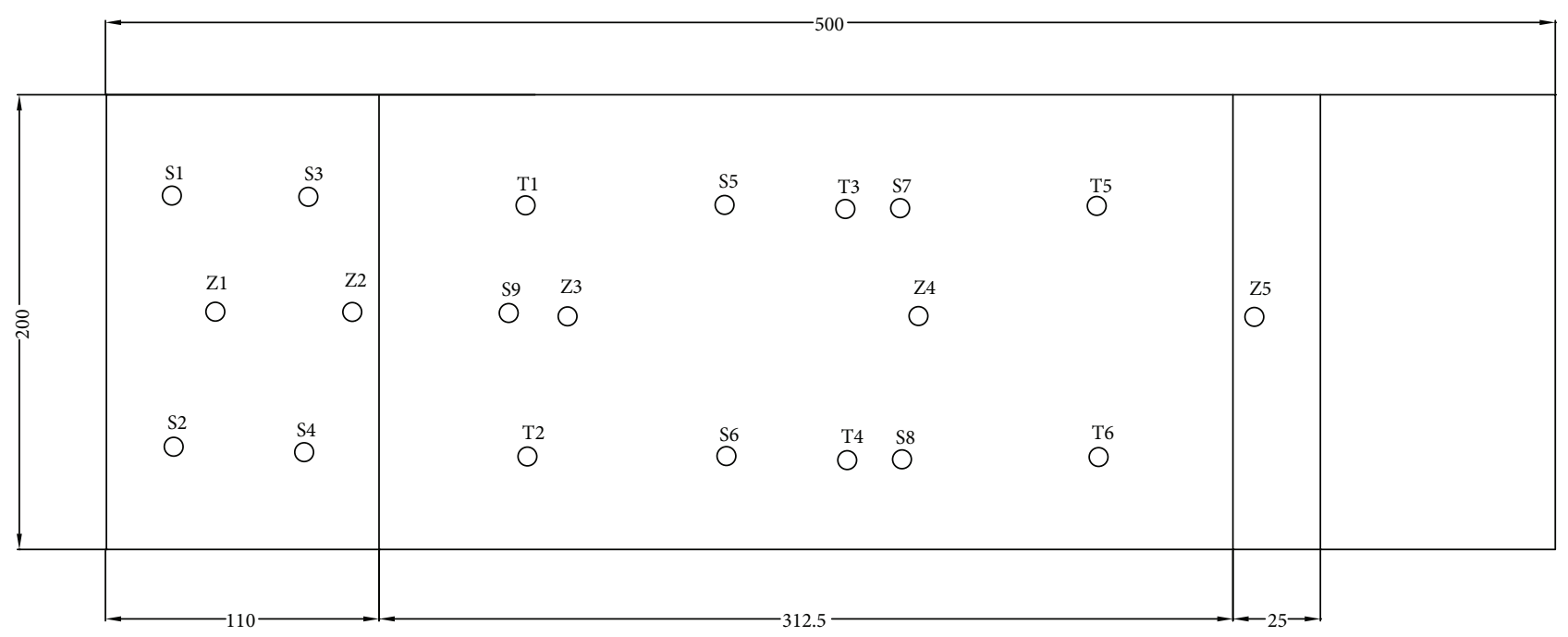

FIgURE 4: Top view of sensor embedding (unit: $\mathrm{cm}$ ). S: osmometer, Z: matric suction sensor, and T: soil pressure gauge.

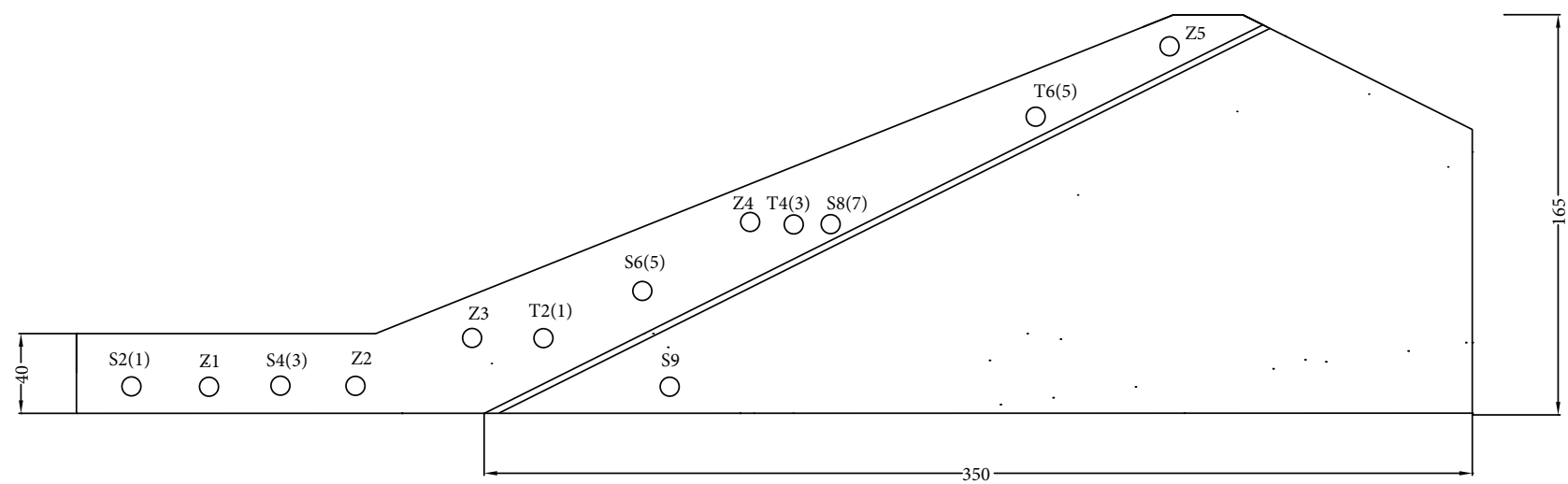

FIGURE 5: Front view of sensor embedding (unit: $\mathrm{cm}$ ). S: osmometer, Z: matric suction sensor, and T: soil pressure gauge.

content at the front of the clay blanket was always high, the suction there increased at a low and steady rate. In the drying process, cracks formed at the connection between the front blanket and the inclined wall, so water content at the back end of the blanket decreased at a high rate of speed, resulting in an increase in suction at the back of the blanket at the 


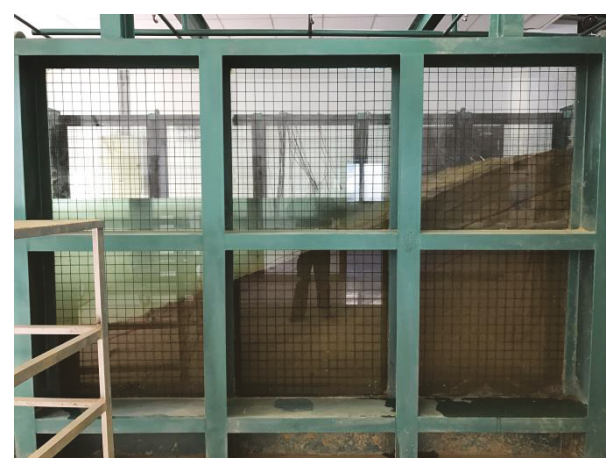

FIGURE 6: Initial water level.

beginning. As drying continued, due to the water supply in section I, water content at the front of the clay blanket did not decrease much more, so the matric suction remained at a relatively stable level. The lower part of the inclined wall was affected by the crack development. These cracks caused the suction to increase initially, but as they ceased widening, water content stabilized and the matric suction increased slowly. Because there were few cracks at the beginning of drying, the increase in matric suction at the middle part of the inclined wall was slow. As the cracks developed along the inclined wall, suction there increased rapidly. Above the five locations where most cracks developed, suction at the dam crest was the most stable. There was no direct lamplight over the dam crest when drying, so water content at this part changed slowly, leading to insignificant change in suction. During the later stage of drying, small cracks appeared in the dam crest. Considering that the clay layer at the dam crest was thin and the sensor was buried shallower, these small cracks also influenced the matric suction, so a slight increase in suction at the dam crest appeared.

3.3. Fluctuating Drought-Flood Period. The initial rainfall intensity was $1.5 \mathrm{~m}^{3} / \mathrm{h}$ during the fluctuating droughtflood period. However, after 5 minutes of rain, it was found that the rain was falling along the outer wall of the compartment, and there was a severe scour around the model. So, the rainfall intensity was reduced to $0.8 \mathrm{~m}^{3} / \mathrm{h}$, and the average rainfall was about $1000 \mathrm{~mm} / \mathrm{h}$ per square meter, as shown in Figure 10. The results during this period are shown in Figure 11.

In this period, the soil was unsaturated, and the appearance of cracks led the water to flow through cracks first and then infiltrate into the soil. In the front of the clay blanket, because the water could infiltrate into the soil from the front and top of the blanket, pore water pressure changed significantly along with the water level, and the pressure was relatively large. At the back of the blanket, due to the development of cracks at the connection between the blanket and inclined wall, the water could seep into the model quickly along cracks. However, in this case, the soil was unsaturated, and the permeability coefficient of the soil was very small, so it was difficult for the water to flow in cracks to enter into the soil. That led to low pore water pressure. The lower part of the inclined wall was also located near the connection between the blanket and inclined wall, so that the change was similar to that at the back of the blanket. Nonetheless, because of the placement of the instrument sensors, the pressure value was smaller than that at the back of the blanket. Additionally, in the middle of the inclined wall, cracks were more developed, and compared with pore water pressure at other parts, the pressure there was the first to decrease and was significantly affected by water level. Generally, due to the effect of drought, all soil was unsaturated, so it was difficult for the water to run through the model. However, from Figure 11(a), the pore water pressure at the bottom of the sand soil layer increased at the beginning of the rainfall process. This was surprising, but during the rainfall process, the rain fell directly to the lower sand soil layer, and because of the large permeability coefficient of the sand soil, the water flow could quickly converge at the bottom of the sand layer, which made the pore water pressure at the bottom increase. As the rain continued, the water level in section III rose gradually, but after it reached a certain height, it was lowered by artificial drainage. Repetition of this process resulted in the fluctuation of pore water pressure in the sandy soil layer.

After the rainfall process, soil pressure at the lower, middle, and upper parts of the inclined wall increased to varying degrees. Among these three areas, soil pressure at the lower part of the inclined wall had the largest growth, and the pressure value was also the largest. In the dam structure, the lower part withstood most of the weight of the slope, and the smallest gravitational force was on the upper part. Therefore, the lower part showed the largest soil pressure. However, for the middle part of the inclined wall, due to the wide cracks there, an unloading phenomenon occurred around the soil pressure gauge that led to the smallest pressure value. Even after cracks had been healed to some degree after the rainfall, the integrity of the soil did not return to its original state. Therefore, the soil pressure at the middle part remained the smallest during the whole process.

During the fluctuating drought-flood period, the matric suction decreased everywhere. Because few cracks developed in the blanket, the suction variation there was small. In contrast, cracks in the inclined wall were wider and more developed than those in other parts of the model dam, so changes of suction at the lower and middle parts of the inclined wall were relatively more obvious than those at other parts. Combined with the variable trend in seepage at this time, pore water pressure was not much changed as the matric suction changed modestly. However, for the middle of the inclined wall, pore water pressure was larger than that during the impoundment period, and both matric suction and pore water pressure changed greatly. Combining related studies with the results of the test, it could be found that the variation of matric suction reflected the change of the permeability coefficient. Therefore, there was a mutual reaction between the matric suction and the permeability coefficient. It was difficult to directly measure the permeability coefficient of each part of the model, but the measurement of the matric suction of the corresponding 


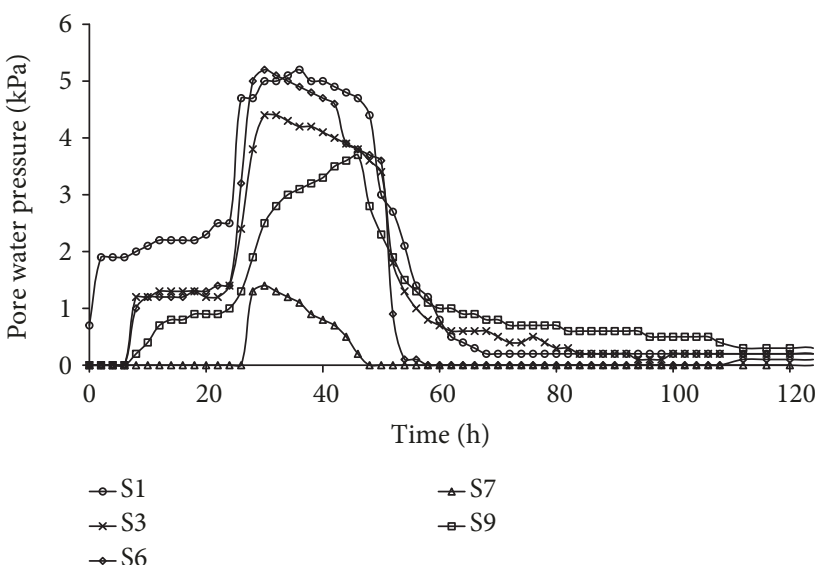

(a) Pore water pressure

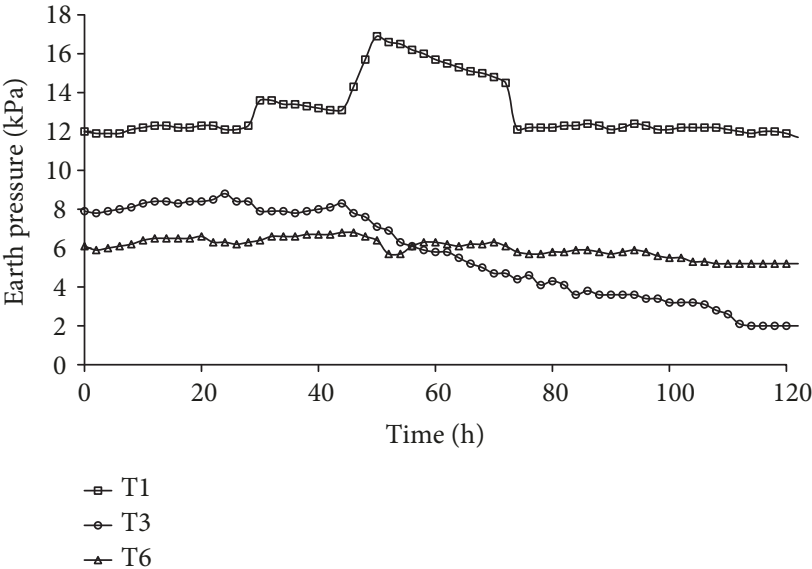

(b) Earth pressure

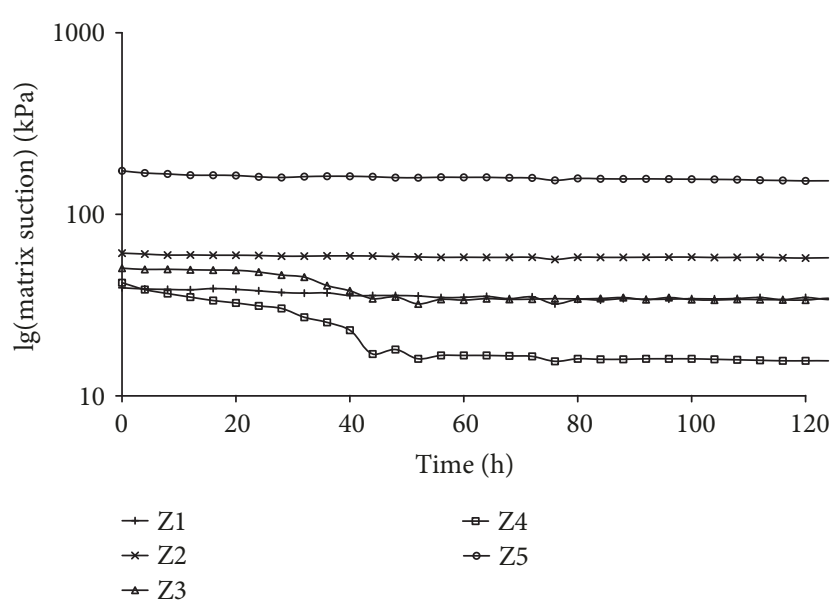

(c) Matric suction

FIGURE 7: Results during the impoundment period.

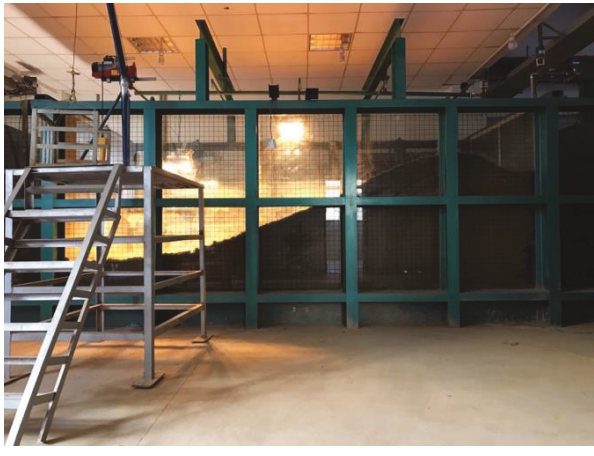

(a)

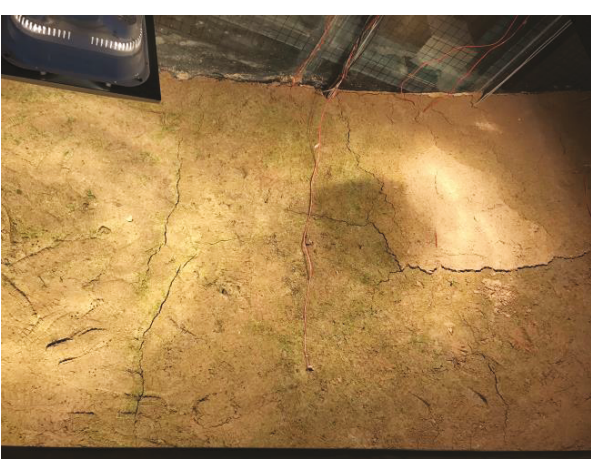

(b)

FIgURE 8: Simulated drought and crack development.

part was possible. The change of the permeability coefficient caused the water infiltration rate to change and affected the change rate of the moisture content, which influenced the variation trend and speed of the matric suction. According to the matric suction, the permeability coefficients at different parts of the dam at different times could be inverted. When the permeability coefficient of the soil was low, it was hard for the water to penetrate into the soil and the pore water pressure increased slowly. At this time, the matric suction value was large. On the contrary, when 


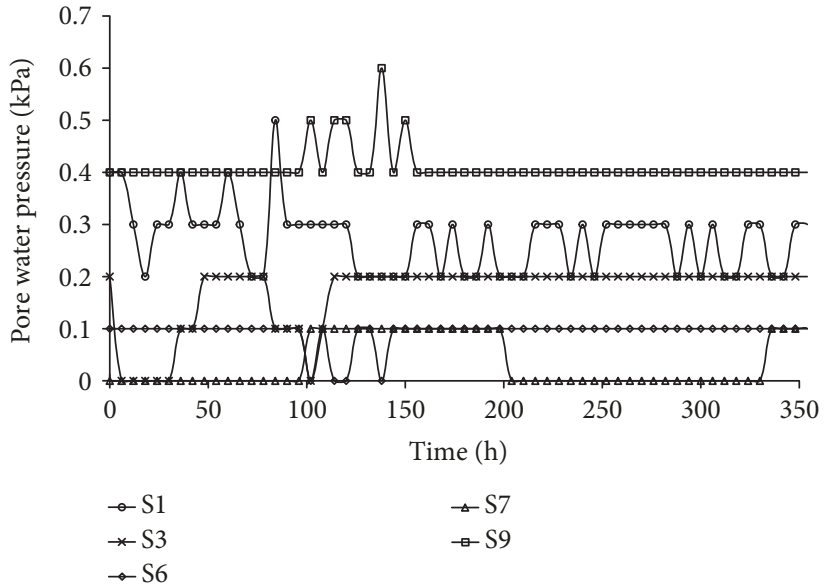

(a) Pore water pressure

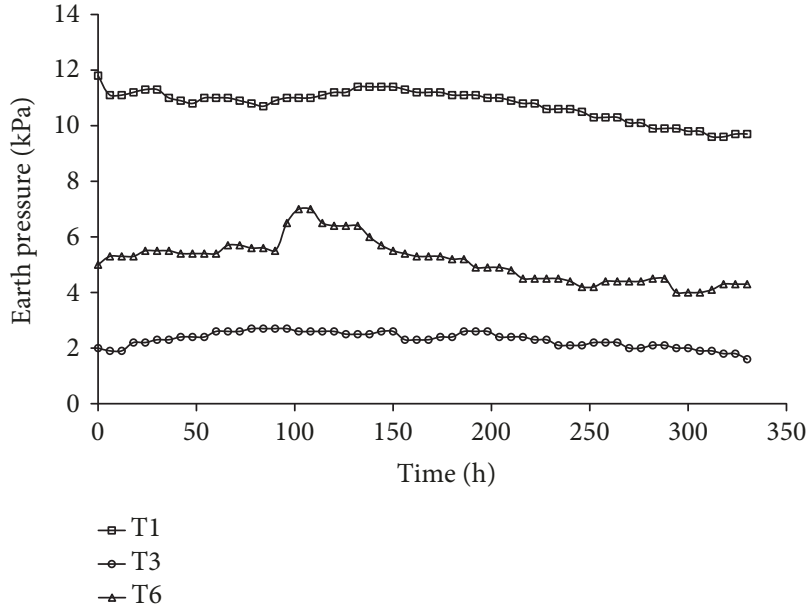

(b) Earth pressure

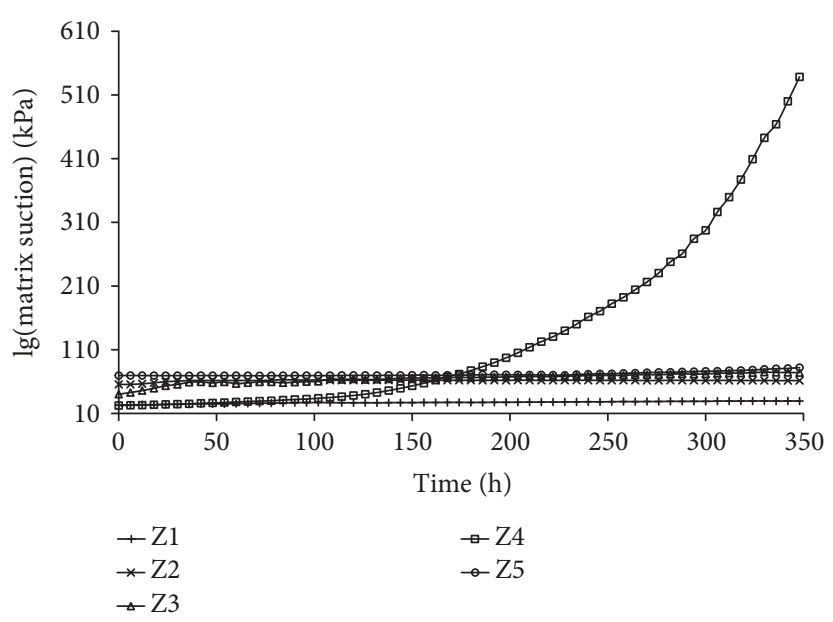

(c) Matric suction

FIGURE 9: Results during the drought period.

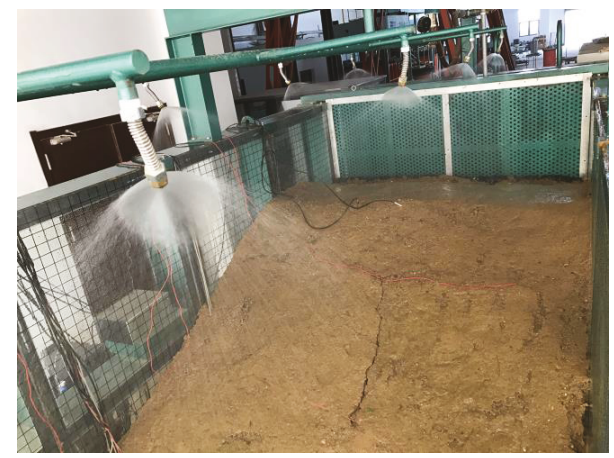

Figure 10: Rainfall and flooding process.

the permeability coefficient of the soil was high, it was easy for the water to penetrate into the soil, which showed that there were a rapid change rate and big amplitude of the pore water pressure. At this time, the matric suction was small.

\section{Conclusion}

Based on a physical model test, the behavior of seepage in an inclined wall dam under fluctuating drought-flood conditions was studied. The main conclusions are as follows:

(1) Cracks developed to different degrees over the surface of the clay soil after drought. Afterwards, the water filled cracks first and then seeped into the surrounding soil during the rainfall process. For areas with shallow or no cracks, the permeability coefficient of the clay layer decreased substantially. For the same water level and duration time, pore water pressure was smaller than that before the drought. However, in the region with cracks, the pore water pressure changed greatly and was much larger than that before the drought.

(2) Cracks could be healed during the rainfall process, but the integrity of the soil was no longer as good as it was in its original state. Therefore, the soil pressure 


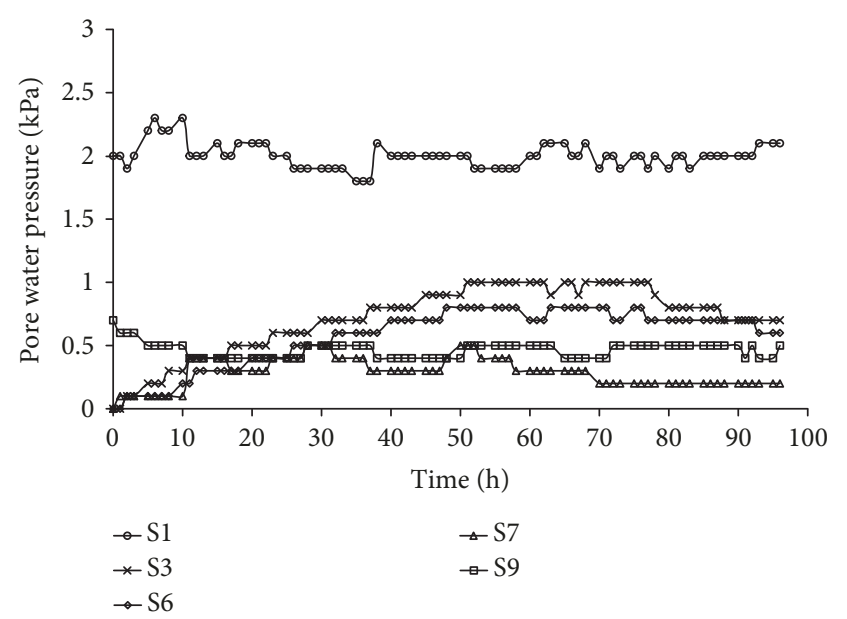

(a) Pore water pressure

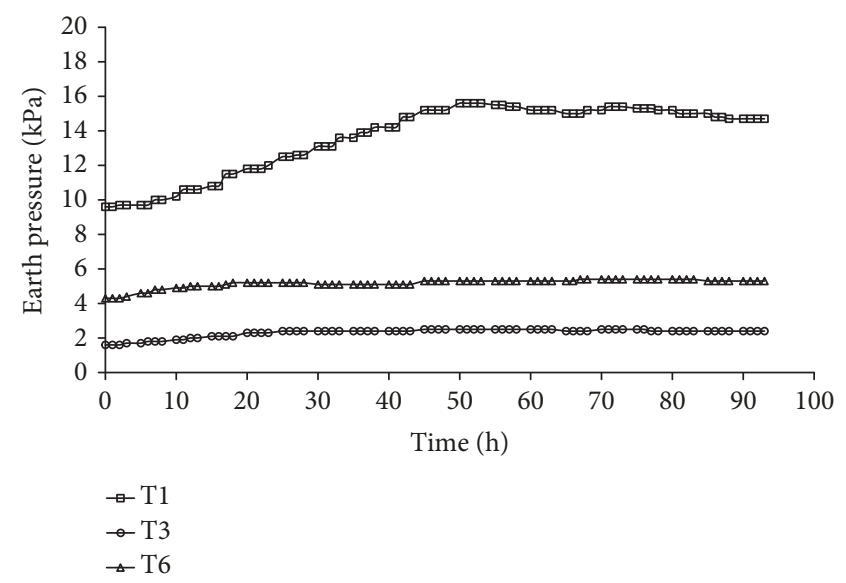

(b) Earth pressure

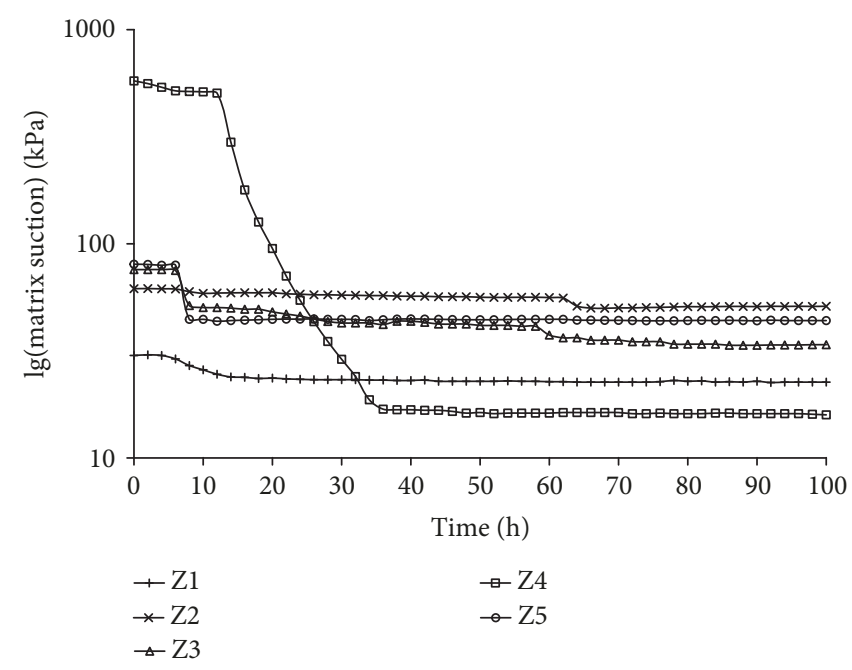

(c) Matric suction

FIGURE 11: Results during the rainfall and flooding period.

in the inclined wall was incoherent, and the upper pressure could not be transferred to the bottom. In this situation, if the weight of the upper soil kept increasing, a landslide would occur.

(3) Changes in matric suction in the region with low development of cracks were relatively small. However, for areas with high crack development, matric suction decreased abruptly during the rainfall. Moreover, the decrease of suction increased the soil permeability in this region, and the weak seepage turned into saturated seepage. In general, this rapid transition in seepage would be detrimental to dam safety.

The results of this study will be useful in monitoring practical engineering projects, such as the Zhaopingtai Reservoir in He'nan Province, China, and other water conservancy dams with inclined earthen walls, and mitigating possible dam failures due to seepage problems.

\section{Data Availability}

The data used to support the findings of this study are available from the corresponding author upon request.

\section{Conflicts of Interest}

The authors declare that there is no conflict of interests regarding the publication of this article.

\section{Acknowledgments}

The research presented in this paper was supported by the National Natural Science Fund (51779155) and Project of Water Conservancy Science and Technology of He'nan Province, China (Grant nos. GG201532 and GG201546). The authors thank Anika B. Newell, from Liwen Bianji, Edanz Group China (http://www.liwenbianji.cn/ac), for editing the English text of the draft of this manuscript. 


\section{References}

[1] A. Ahmed and M. Maddaus, "Understanding the impact of climate change on water resources sustainability-AWWA's Climate Change Committee report," in World Environmental and Water Resources Congress 2011, pp. 1347-1356, Palm Springs, CA, USA, 2011.

[2] J. C. Huang and P. Makar, "Reclamation's research on climate change impact on reservoir capacity," in World Environmental and Water Resources Congress 2013, pp. 1202-1212, Cincinnati, OH, USA, 2013.

[3] Y.-I. Moon, T.-S. Oh, M.-S. Kim, and S.-S. Kim, “A drought frequency analysis for Palmer Drought Severity Index using boundary kernel function," in World Environmental and Water Resources Congress 2010, pp. 2708-2716, Providence, RI, USA, 2010.

[4] J. Feng, D. Yan, C. Li, Y. Gao, and J. Liu, "Regional frequency analysis of extreme precipitation after drought events in the Heihe River Basin, Northwest China," Journal of Hydrologic Engineering, vol. 19, no. 6, pp. 1101-1112, 2014.

[5] X. Y. He, Z. Y. Wang, J. C. Huang, and L. Q. Ding, "Statistics and preliminary analysis of the dam crash of China reservoir," in Proceedings of the 2005 Academic Annual Conference of China Water Conservancy Association-Risk Management of Water and Drought Disasters, pp. 321-329, Qing Dao, China, 2005.

[6] X. Y. He, Z. Y. Wang, and J. C. Huang, "Analysis on the spatial distribution of dam-failure in China," Journal of Catastrophology, vol. 23, pp. 1-4, 2008.

[7] I. Sasanakul, S. L. Gassman, C. E. Pierce et al., "Dam failures from a 1000-year rainfall event in South Carolina," in Geotechnical Frontiers 2017, pp. 114-124, Orlando, FL, USA, 2017.

[8] V. Novák, J. Šimåunek, and M. T. van Genuchten, "Infiltration of water into soil with cracks," Journal of Irrigation and Drainage Engineering, vol. 126, no. 1, pp. 41-47, 2000.

[9] Z. Q. Huang, J. Yao, Y. Y. Wang, and K. Tao, "Numerical study on two-phase flow through fractured porous media," Science China Technological Sciences, vol. 54, no. 9, pp. 24122420, 2011.

[10] Z. H. Ge, B. H. Fan, Q. Y. Fen, and Y. H. Wang, "The study of water-flow in a clay fracture," Journal of Geological, vol. 67, pp. 159-167, 1993.

[11] J. L. Fan, The Test Research on Soil Landslide's Stability Influenced by Crack Water, Chengdu Univerisity of Technology, 2008.

[12] S. Kakuturu and L. N. Reddi, "Mechanistic model for selfhealing of core cracks in earth dams," Journal of Geotechnical and Geoenvironmental Engineering, vol. 132, no. 7, pp. 890901, 2006.

[13] Z. F. Liu, "Seepage calculation of pavement cracks," Journal of Jiang Xi Water Technology, vol. 22, pp. 7-22, 1986.

[14] S. Khandelwal, M. Sanchez, and Z. Medina-Cetina, "Effect of depth of desiccation cracks on earth embankments," in Geo-Congress 2013, pp. 800-803, San Diego, CA, USA, 2012.

[15] R. L. Handy and M. Lustig, "Tension cracks in a compacted clay embankment," Journal of Geotechnical and Geoenvironmental Engineering, vol. 143, no. 7, article 06017006, 2017.

[16] Z. L. Ge, "Leaking and warping through cracks of earth dam blanket," Hydro-Science and Engineering, vol. 41, pp. 36-44, 1982.
[17] H.-J. Vogel, H. Hoffmann, A. Leopold, and K. Roth, "Studies of crack dynamics in clay soil: II. A physically based model for crack formation," Geoderma, vol. 125, no. 3-4, pp. 213223, 2005.

[18] J. H. Li and L. M. Zhang, "Study of desiccation crack initiation and development at ground surface," Engineering Geology, vol. 123, no. 4, pp. 347-358, 2011.

[19] H. Hoang, D. Hoxha, N. Belayachi, and D. P. Do, "On the impact of cracking on unsaturated hydrous properties of porous materials," in Fifth Biot Conference on Poromechanics, pp. 1560-1569, Vienna, Austria, 2013. 

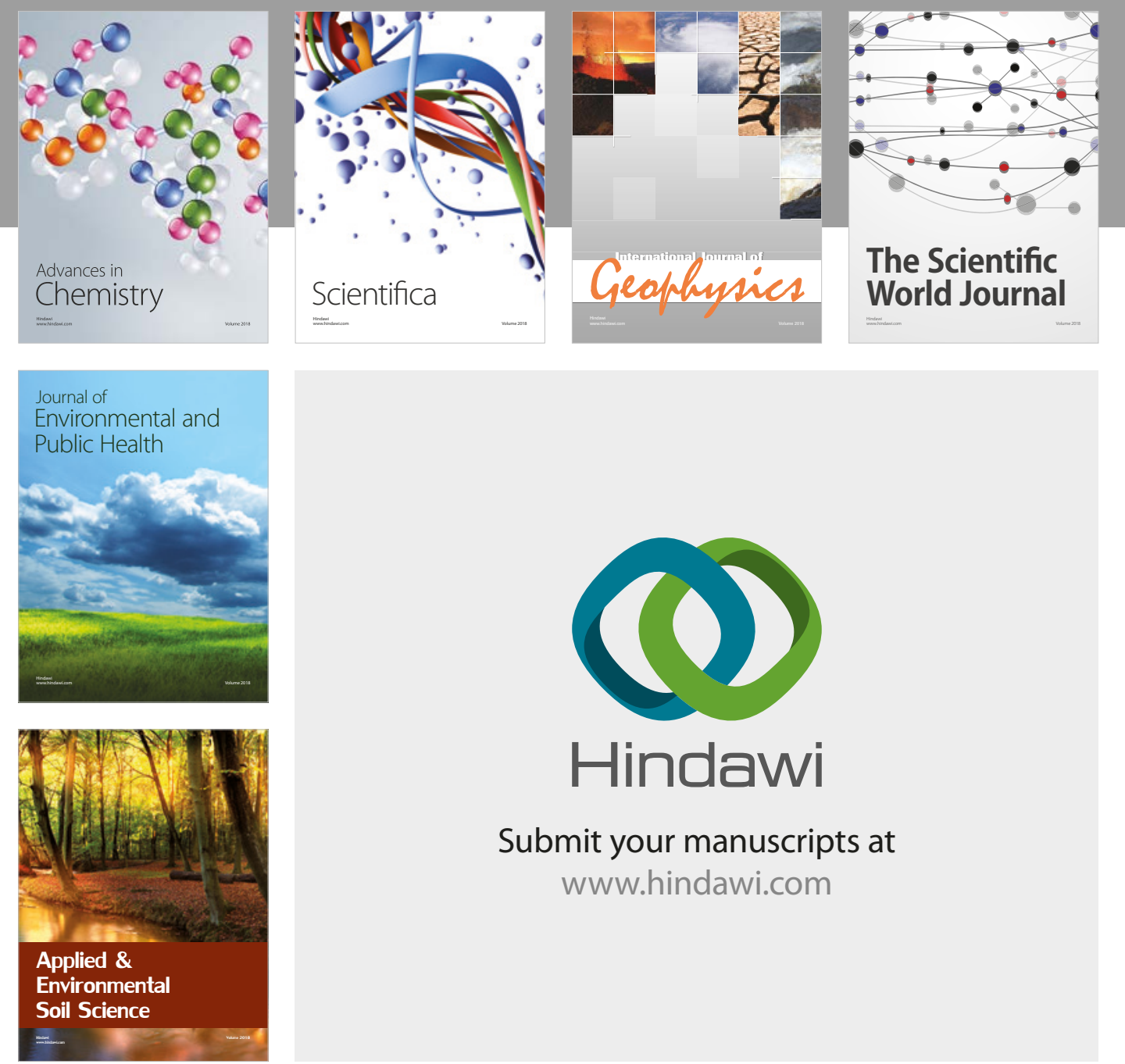

The Scientific

\section{World Journal}
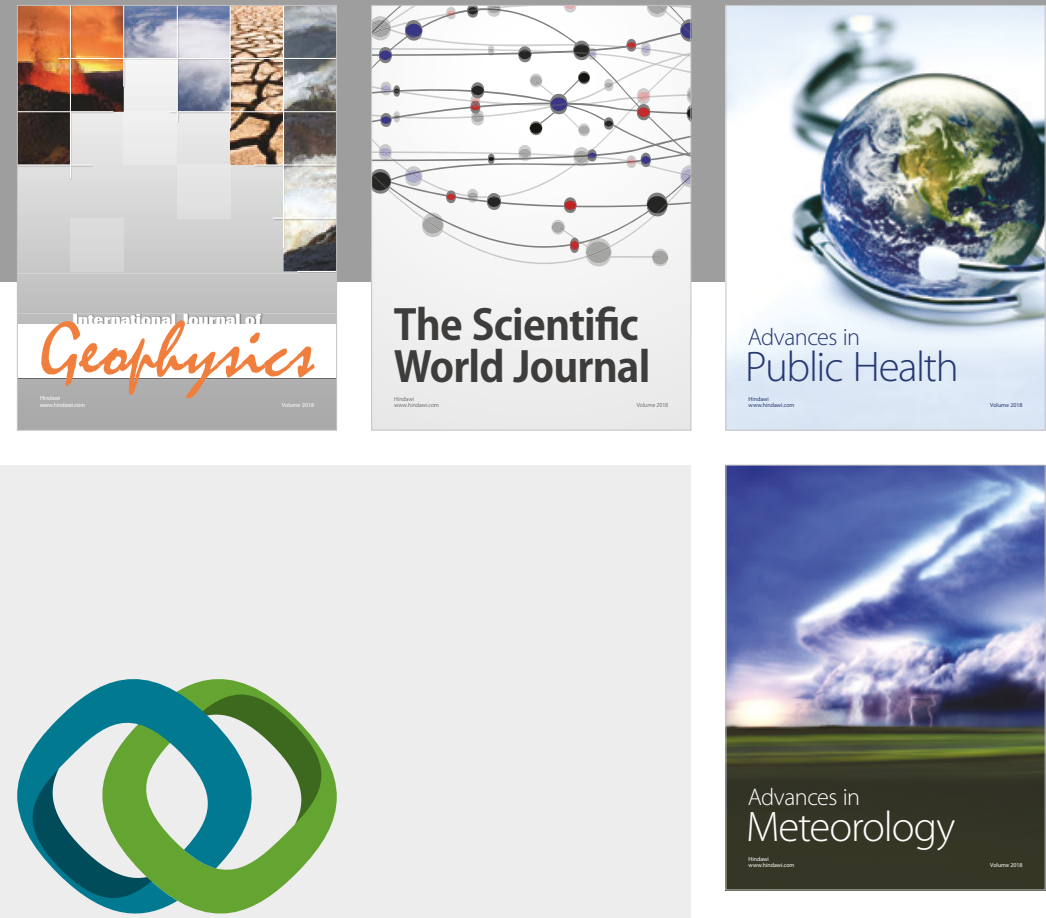

Advan

Public Health

\section{Hindawi}

Submit your manuscripts at

www.hindawi.com
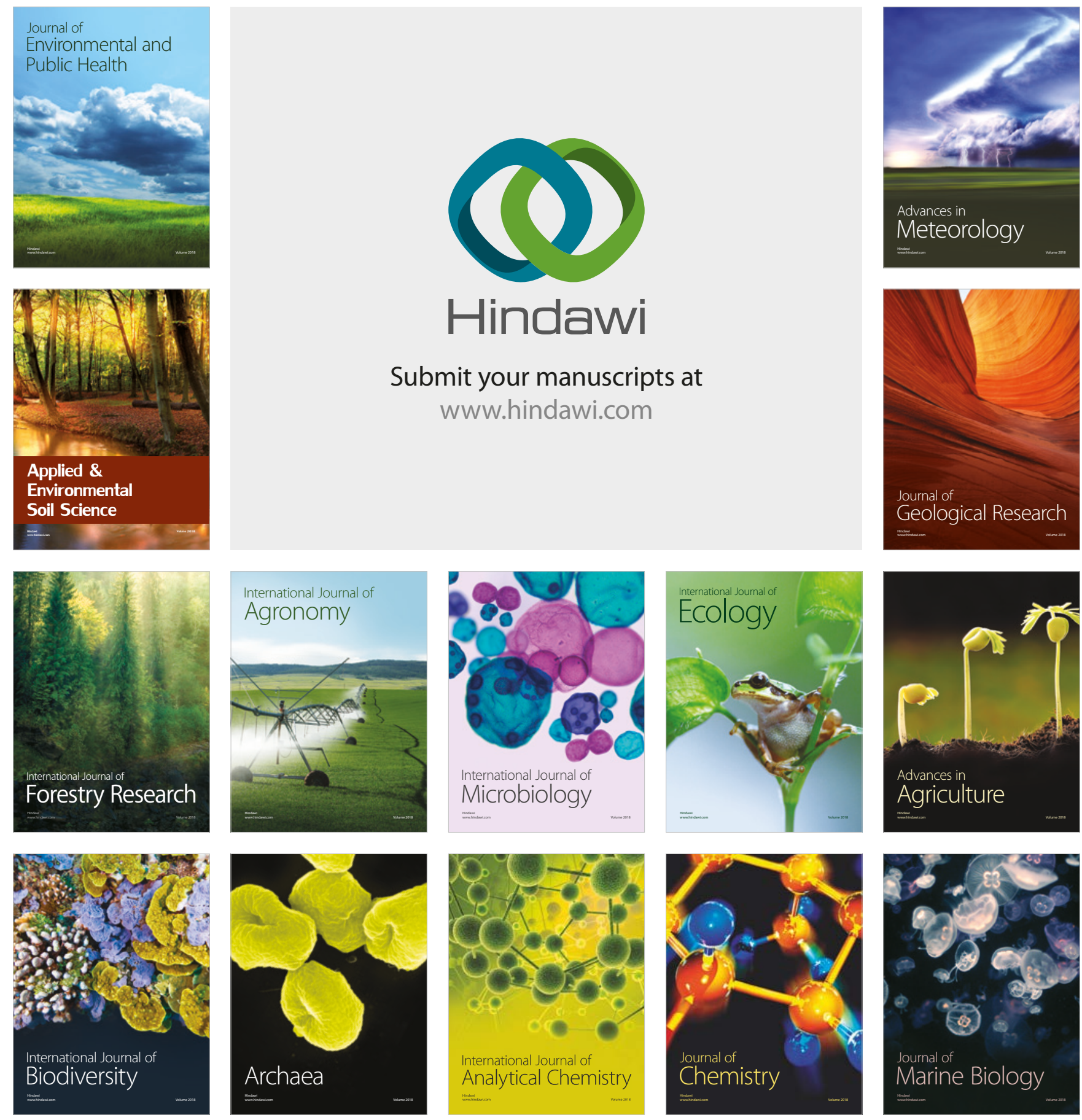